\title{
High Voltage Insulation Properties of HFO1234ze
}

\section{Journal Article}

Author(s):

Koch, Myriam; Franck, Christian (i)

Publication date:

2015-12

Permanent link:

https://doi.org/10.3929/ethz-b-000103183

Rights / license:

In Copyright - Non-Commercial Use Permitted

\section{Originally published in:}

IEEE Transactions on Dielectrics and Electrical Insulation 22(6), https://doi.org/10.1109/TDEl.2015.005118 


\section{(C) 2015 IEEE.}

Personal use of this material is permitted. Permission from IEEE must be obtained for all other uses, in any current or future media, including reprinting/republishing this material for advertising or promotional purposes, creating new collective works, for resale or redistribution to servers or lists, or reuse of any copyrighted component of this work in other works." 


\title{
High Voltage Insulation Properties of HFO1234ze
}

\author{
M. Koch and C. M. Franck \\ ETH Zurich \\ Power Systems and High Voltage Laboratories \\ Physikstrasse 3 \\ 8092 Zurich, Switzerland
}

\begin{abstract}
Recently it was shown that it is possible to predict the breakdown voltages of arbitrary electrode configurations under standard voltage applications for electron attaching gases with a stepped leader model originally proposed for $\mathbf{S F}_{6}$. In this contribution this model was applied to the hydrofluoroolefin HFO1234ze. The parameters, which are necessary for the modeling, are derived from measurement of statistical and formative time lags in an electrode configuration with a homogeneous background field with a small protrusion. The parameters are used to predict the breakdown voltage for technical relevant geometries and standard voltage wave shapes. To verify these predictions, breakdown experiments in nearly homogeneous and strongly inhomogeneous field configurations with $\mathrm{AC}$ and lightning impulse voltage application of both polarities were performed. The hydrofluoroolefin exhibits insulation properties which are quite similar to those of $\mathrm{SF}_{6}$. Therefore it could be considered as admixture for high voltage gaseous insulations or as replacement in medium voltage equipment. For applications using the pure gas the temperature and pressure range has to be limited to prevent liquefaction. The good match between the simulations and the experiments gives evidence that the model can be applied to a broad range of other novel electron attaching gases as well.
\end{abstract}

Index Terms — Gas insulation, gas discharges, dielectric breakdown, modeling.

\section{INTRODUCTION}

THE discussion about replacing sulfur hexafluoride $\left(\mathrm{SF}_{6}\right)$ as insulation gas in high voltage equipment is as old as the utilization of the gas itself. While research up to the early 1980s predominantly focused on pure gases, today mainly gas mixtures are of common interest [1-5]. The traditional way to investigate the dielectric properties of gases and gas mixtures was characterized by breakdown experiments with relevant electrode geometries and voltage waveforms, e.g. [2].

Recently, a procedure to identify and quantify novel highvoltage insulation gases was proposed, consisting of a quantum-chemical screening of molecules, swarm parameter measurements of suitable gases from the screening process and prediction of the breakdown behavior of the most promising candidates [6]. In this procedure the prediction of the breakdown is based on a model for $\mathrm{SF}_{6}$ proposed in literature [7-9]. In former works it was already shown that it is possible to adapt this model to other electron attaching gases such as octafluoropropane $\left(\mathrm{C}_{3} \mathrm{~F}_{8}\right)$ [10] and tetrafluoromethane $\left(\mathrm{CF}_{4}\right)$ [11]. Those gases were chosen because they are well known from literature and thus, the calculations could be compared to literature values.

The hydrofluoroolefin HFO1234ze (trans-1,3,3,3tetrafluoroprop-1-ene, chemical formula: $\left.\mathrm{C}_{3} \mathrm{H}_{2} \mathrm{~F}_{4}\right)$ is a gas which was only recently tested and patented [12-14] for use in

Manuscript received on 11 December 2014, in final form 3o March 2015, accepted 28 April 2015. high voltage equipment. But no details are known about the electric properties. The gas showed good performance in the quantum-chemical analysis [15], is not harmful [16] and can be easily purchased. In [13] the critical field strength of HFO1234ze was measured to 0.8 that of $\mathrm{SF}_{6}$. This agrees with quantum-chemical simulations which predicted a critical field strength of $1 \pm 0.35$ times that of $\mathrm{SF}_{6}[15,17]$. The pressure reduced effective ionization coefficient and the pressure reduced critical field strength determined in a swarm experiment showed a pronounced linear pressure dependence without saturation in the range up to $40 \mathrm{kPa}$ [18] and the molecule shows strong electron attaching properties. This is manifested in the steep slope of the pressure reduced effective ionization coefficient in the range of the critical electric field strength. The boiling point of HFO1234ze is $-19^{\circ} \mathrm{C}$. This corresponds to a vapor pressure of $0.42 \mathrm{MPa}$ at room temperature [16]. The global warming potential is 6 on a 100 year time horizon [19], and the ozone depletion potential is zero [14].

The understanding of the thermodynamic properties of the isomer HFO1234yf is better. This molecule is proposed as substitute for air conditioning and heat pump devices. But this is controversial [20]: The thermophysical properties of both derivates are very similar $[21,22]$ but HFO1234yf is extremely flammable (risk phrase R12, GHS hazard statement H220) [23]. Both molecules decompose to trifluoroacetic acid (TFA) in the atmosphere, which cannot be further degraded 
and thus, will accumulate in the atmosphere when released extensively [19,24,25].

For this contribution HFO1234ze is chosen because it is less flammable. The aim is to investigate if it is possible to assess the high voltage insulation capability of HFO1234ze only by using the above mentioned model by predicting the breakdown field strength in arbitrary geometries of this quite unknown insulation gas. In section 2 the experimental and simulative methods are provided. For the breakdown modeling some empirical parameters are necessary, which are described in section 3. The breakdown field strengths are calculated and compared to experimental results in section 4 , and a conclusion and an outlook are provided in section 5 .

\section{METHODS \\ 2.1 SIMULATION OF PARTIAL DISCHARGES AND BREAKDOWN FIELDS}

Seeger et al [7] describe a model to calculate the partial discharge and breakdown fields for a certain electrode configuration based on the stepped leader process [26]. The stepped leader process assumes the formation of a corona in front of a protrusion. The free electrons attach and the subsequent movement of the charged particles leads to heating and thus, to a conductive channel. This conductive channel leads to a leader section with a substantially lower voltage drop. This leads to a new corona in front of the leader section. For the leader inception two mechanisms are known: the stem and the precursor mechanism.

The field strengths calculated with this model are represented as a quantity $x$, which denotes the field strength of the homogeneous background field (i.e. applied voltage divided by gap distance) normalized to the critical field strength at the given pressure. The following parameters are obtained through the calculations:

1. The streamer inception field strength $x_{\text {inc }}$ calculated with the streamer criterion.

2. The lower limit of breakdowns $x_{\min }$, which is determined by the stem mechanism for leader inception. For this mechanism the whole charge $\left(\alpha_{1}=1\right)$ of the streamer corona heats the leader channel.

3 . The upper limit of delayed breakdowns $x_{\max }$. The leader incepts via precursor mechanism and thus, only a small fraction $\alpha_{2}<0$ of the corona charge takes part in the channel heating.

The initial streamer radius $R$ is an important factor in the model and scales inversely with the pressure $p$ [26]:

$$
R=\frac{C_{\mathrm{s}}}{p}
$$

The simulation contains three a priori unknown parameters: the scaling parameters for the streamer radii $C_{\mathrm{s} \text {,pos }}$ and $C_{\mathrm{s} \text {,neg }}$ and the fraction $\alpha_{2}$ of the corona charge of the precursor mechanism. These can be derived from measurements of the statistical and formative time lags as described in section 2.2. The constraints of the simulation are summarized in [10]. Further parameters for the simulation are given in table 1.

Additionally, some thermodynamic properties of the gas have to be known: the enthalpy, the normalized density and the critical field strength. They are calculated on the basis of the thermal dissociation products. For the determination of the dissociation products the Cantera software is used [27]. As input parameter the tool needs the so called NASA-7polynoms for all involved species. They are only available for the HFO1234yf molecule [28]. As the thermal properties of HFO1234yf and HFO1234ze are quite similar [21], the polynomials of HFO1234yf are used for the thermodynamic simulations. For details of the calculation see [10]. The thermal dissociation of HFO1234 starts at about $900 \mathrm{~K}$ according to the simulation.

The computation of the streamer integral requires the effective ionization coefficient $\alpha_{\text {eff }} / p$ and the critical number of electrons $K$. According to [29] $K=10.5$ is chosen. The pressure reduced effective ionization coefficient $\alpha_{\text {eff }} / p$ and thus also the pressure reduced critical field strength $(E / p)_{\text {crit }}$, determined in a swarm experiment, show a strong pressure dependence [18]: the pressure reduced critical field strength increases linearly with increasing pressure and no saturation was observed up to $40 \mathrm{kPa}$ in the swarm experiment. Therefore, AC breakdown experiments in homogeneous electric fields are performed to estimate the critical field strength in the higher pressure range (see sections 2.4 and 3.3). Smooth electrodes (aluminum) with Rogowski profile at a distance of $15 \mathrm{~mm}(0.05 \mathrm{MPa}, 0.1 \mathrm{MPa}$ and $0.15 \mathrm{MPa}), 10 \mathrm{~mm}$ (0.15MPa, $0.2 \mathrm{MPa}$ and $0.25 \mathrm{MPa})$ and $8 \mathrm{~mm}(0.15 \mathrm{MPa}$ and $0.2 \mathrm{MPa}$ ) are used.

Table 1. Parameters for the simulation of the partial discharge inception fields and breakdown fields in HFO1234ze.

\begin{tabular}{|c|c|c|c|}
\hline Gas parameter & & Value & \\
\hline Normalized density & $(\rho / p)_{0}$ & $4.7 \cdot 10^{-5} \mathrm{~kg} / \mathrm{Pa} \mathrm{m}$ & [21] \\
\hline Velocity of sound & $c_{0}$ & $151.6 \mathrm{~m} / \mathrm{s}$ & [21] \\
\hline \multicolumn{4}{|l|}{ Scaling factor } \\
\hline Expansion & $C_{\mathrm{ex}}$ & 0.6 & [7] \\
\hline Mach number & $\beta$ & 0.1 & [7] \\
\hline Stem mechanism & $\alpha_{1}$ & 1 & [7] \\
\hline $\begin{array}{l}\text { Precursor } \\
\text { mechanism }\end{array}$ & $\alpha_{2}$ & 0.03 & \\
\hline $\begin{array}{l}\text { Positive streamer } \\
\text { radius }\end{array}$ & $C_{\mathrm{s}, \mathrm{pos}}$ & $1.5 \mathrm{~Pa} \mathrm{~m}$ & \\
\hline $\begin{array}{l}\text { Negative streamer } \\
\text { radius }\end{array}$ & $C_{\mathrm{s}, \text { neg }}$ & $2.7 \mathrm{~Pa} \mathrm{~m}$ & \\
\hline
\end{tabular}

\subsection{SETUP FOR PARAMETER DETERMINATION}

The simulation method presented in section 2.1 contains the a priori unknown values $C_{\mathrm{s} \text {,pos }}, C_{\mathrm{s} \text {,neg }}$ and $\alpha_{2}$. Those parameters can be extracted from measurements of the statistical and formative time lags. For the measurements a circuit as shown in figure 1 is used. It consists of a two stage cascade circuit according to Greinacher (or Cockroft-Walton) rectifying and doubling the $\mathrm{AC}$ voltage and charging the capacitance $C_{2}$ with up to $200 \mathrm{kV}$. With a switch the high voltage is applied to the test object resulting in a step voltage with a steep front (500 ns rise time), without overshoot. The voltage is measured with a capacitive voltage divider with $C_{3}=150 \mathrm{pF}$ and a ratio of 2170 . The test object itself consists of two plane aluminum electrodes with $15 \mathrm{~mm}$ distance forming a homogeneous background field. A needle with a tip 
radius of $200 \mu \mathrm{m}$ is inserted in the ground electrode, electrically insulated, and adjusted to a protrusion height of $1 \mathrm{~mm}$. Discharges are observed with a photomultiplier and a current monitor (Pearson Model 2877). Further details can be found in [10]. Measurements are run at pressures of $0.1 \mathrm{MPa}$, 0.15 MPa, 0.2 MPa, 0.25 MPa and 0.3 MPa.

With this setup the time lags of discharges could be observed. The statistical time lag $t_{\mathrm{s}}$ denotes the time between the voltage application and the first partial discharge. The time between the first partial discharge and the breakdown is described by the formative time lag $t_{\mathrm{f}}$. The total time to breakdown is the sum of these two time lags.

For the investigation of the lowest partial discharge inception field strength, a pulsed $x$-ray source was used during the measurements at $0.2 \mathrm{MPa}$. The $\mathrm{x}$-ray source provides start electrons in the critical volume (the volume at the tip, where the field strength exceeds the critical field strength) and hence, eliminates the statistical time lag [30]. For experimental reasons, a delay of $20 \mu \mathrm{s}$ between the voltage rise and the $\mathrm{x}$ ray application is inserted. With this method it is possible to exactly determine $x_{\text {inc }}$ [31]. Especially for the positive polarity of some gases, the evaluation of the lowest breakdown voltage $x_{\min }$ without x-rays is difficult $[10,11]$. Providing first electrons artificially enabled the determination of the breakdown limit.

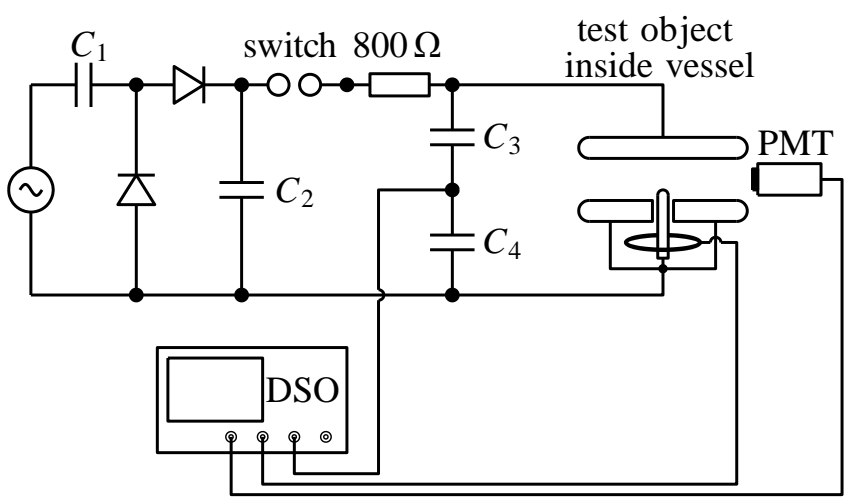

Figure 1. Schematic of the circuit generating a step-voltage with a fast rising front. The applied voltage is measured with a capacitive voltage divider, the discharges are observed with a current monitor and a photomultiplier $\left(C_{2}=6 \mathrm{nF}, C_{3}=150 \mathrm{pF}, \mathrm{V}_{\mathrm{HV}} / \mathrm{V}_{\mathrm{LV}}=2170\right)$.

\subsection{PREDICTION OF BREAKDOWN VOLTAGES}

Based on the simulation of the discharge inception field $x_{\text {inc }}$ and the lower and upper limit of delayed breakdowns $x_{\min }$ and $x_{\max }[7]$, Bujotzek and Seeger proposed a technique to predict the breakdown voltages of various technical relevant geometries under standard voltage forms [8]. This simulation takes also into account the statistical time lag to the appearance of a first electron for both polarities. The statistical time lag for negative protrusions is independent of the gas and is determined by the cold field emission of electrons from the electrode and can be modeled according to the FowlerNordheim equation [32, 33]. In the case of positive protrusions, the start electrons are provided by detachment from negative ions drifting towards the high field at the protrusion tip [9]. Detachment is the main source of free electrons for strongly electron attaching gases ([35] and references therein). For each geometry and both polarities the values of $x_{\text {inc }}, x_{\min }, x_{\max }$ and the statistical time lag are calculated for a certain pressure range. The results are compared and only if the streamer inception and the breakdown criterion are satisfied and a first electron is available, the breakdown is possible.

\subsection{MEASUREMENT OF THE BREAKDOWN FIELD STRENGTH}

For the validation of the simulations according to section 2.3, AC and lightning impulse (LI) breakdown measurements for two geometries were performed:

(A) Rogowski-profile electrodes with a substantial surface roughness. Due to an improved manufacturing process during the experiment series, the electrodes for the AC measurements had a surface roughness of approximately $400 \mu \mathrm{m}$ and those for the LI experiments of approximately $300 \mu \mathrm{m}$. The roughness was manufactured as helical cut (similar to a thread but planar) at the high voltage side. This gives a reproducible and defined surface roughness. The distance of the electrodes was adjusted to $15 \mathrm{~mm}$.

(B) A $20 \mathrm{~mm}$ protrusion with $200 \mu \mathrm{m}$ tip radius, the distance of the plane electrodes was adjusted to $40 \mathrm{~mm}$. This results in a gap distance of $20 \mathrm{~mm}$.

The AC breakdown voltages are determined with a progressive stress test. 41 voltage rises with a gradient of $20 \mathrm{kV} / \mathrm{s}$ are applied to the electrode configuration with a cascade of two MWB transformers with a maximum voltage of $200 \mathrm{kV}$ rms. The rise of the voltage started at zero voltage, was ramped up to $10 \mathrm{kV} \mathrm{rms}$ and kept constant for $10 \mathrm{~s}$ to remove the ions from the gas gap. Then the voltage was increased until breakdown. A total series resistance of $100 \mathrm{k} \Omega$ between the transformer and the test vessel and a fast switchoff device is used for the protection of the electrodes in case of breakdown. The breakdown voltage is measured with a $50 \mathrm{pF}$ capacitive voltage divider and a peak voltmeter (MU15, High Volt). The voltage of some experiment series was additionally monitored with an oscilloscope (RTO1024, $2 \mathrm{GHz}, 10 \mathrm{GSs}^{-1}$ ) to determine if the breakdown occurred during the positive or the negative half wave. The mean breakdown voltage and the standard deviation are calculated according to [34]. The series of measurements are tested with trend tests ( $\mathrm{F}$ - and t-test) and with the iteration test (statistical independence).

The lightning impulse breakdown voltages are measured with two to four stages of an eight stage 1.6 MV Marx generator (Haefely/High Volt). The up-and-down method is used with about 40 experiments per pressure and polarity. A waiting time of 5 or $10 \mathrm{~min}$ is inserted in between the experiments to allow for equilibration of the ion density. The mean breakdown voltage and the standard deviation for each series are determined according to [34]. The iteration test is applied to check for statistical independence. All results shown in figure 4 passed the iteration test.

\section{PARAMETER DETERMINATION 3.1 TIME LAG MEASUREMENTS}

Measurements of the statistical and formative time lags with the setup described in section 2.2 were carried out at $0.1 \mathrm{MPa}$, 
0.15 MPa, 0.2 MPa, 0.25 MPa and 0.3 MPa in HFO1234ze. At $0.2 \mathrm{MPa}$ additional experiments with $\mathrm{x}$-ray application are performed. As example, figure 2 shows the results of the investigations with $0.2 \mathrm{MPa}$ pressure and positive and negative tip.

The evaluation of the pulses made some difficulties because the light emission of HFO1234ze in the range of the spectral response of the photomultiplier was poor. The patterns of time lags without $\mathrm{x}$-ray application are similar to those of other gases. The statistical time lags $t_{\mathrm{s}}$ start in the range of seconds and decay to microseconds. This time range is a lower boundary due to the voltage rise. Time lags above some seconds cannot be detected with the setup. The partial discharges start at lower voltages for the negative protrusion.
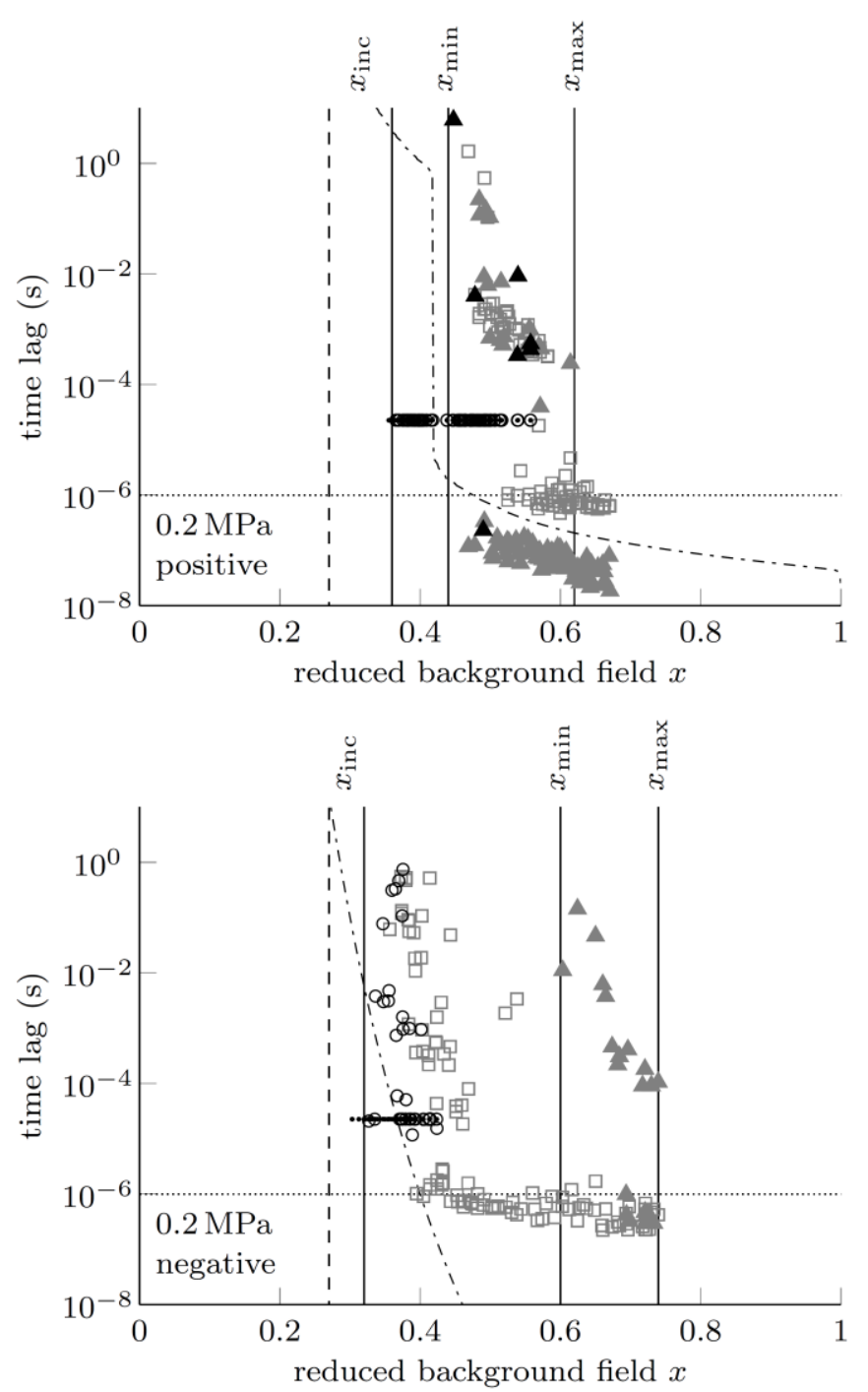

Figure 2. Statistical ( $\square$ without and 0 with $\mathrm{x}$-rays) and formative ( $\triangle$ without and $\boldsymbol{\Delta}$ with $\mathrm{x}$-rays) time lags at $0.2 \mathrm{MPa}$. The small dots mark the time of the $\mathrm{x}$-ray application. The vertical solid lines indicate the experimental limits of $x_{\text {inc }}, x_{\min }$ and $x_{\max }$, the broken line the calculated inception field. The dotted line gives the upper limit of the time to the maximum of the applied voltage. The calculated boundary for $t_{\mathrm{s}}$ is marked by the dashed-dotted line.

Breakdowns are observed with delays for both polarities, but disruptions at positive tips start at lower field strength. For the positive case, breakdowns start at fields only slightly above the first observed partial discharges. For negative protrusions, a substantial field range is in between the lowest voltage where only partial discharges are detected and the lowest breakdown voltage. Looking at the whole pressure range investigated, the lowest reduced field strength for only partial discharges and the lowest reduced field strength for breakdowns (which denotes $x_{\min , \exp }$ ) decrease with increasing pressure for both polarities.

With the application of x-rays shortly after the voltage reached its maximum, electrons for starting an avalanche are provided. In HFO1234ze the lowest breakdown field strengths for positive protrusions are in general higher than the fields of the first observed partial discharge without breakdown (in contrary to e.g. [10]). Thus, the focus of the experiments with $\mathrm{x}$-rays is on the partial discharge inception field strengths, which are determined for $x_{\text {inc,pos }}=0.36$ and $x_{\text {inc,neg }}=0.32$, respectively.

The statistical time lags occurring with the positive tip and $\mathrm{x}$-rays are limited to the delay of the x-ray pulse after the voltage application (about $20 \mu \mathrm{s}$ ). The inception field strength $x_{\text {inc,pos }}$ could be reproduced in independent experiment runs. Above this field strength all experiments showed a discharge pulse if $\mathrm{x}$-rays were applied. The behavior in the negative case is clearly different. Although start electrons were provided, not every $\mathrm{x}$-ray pulse led to a discharge above $x_{\text {inc,neg. }}$. Further, about half of the partial discharges showed statistical time lags substantially longer than the $20 \mu$ s delay of the x-ray application. The distribution of those delayed discharges is similar to the ones without $\mathrm{x}$-ray, but they are shifted towards lower reduced field strengths. In a second experiment run no discharge was observed until $x=0.36$ was reached.

\subsection{TIME TO FIRST ELECTRON}

The average time to the availability of a start electron for avalanche formation is crucial for the breakdown development. The description of this quantity can be extracted from the measurements of the statistical time lags without $\mathrm{x}$ ray application.

\subsubsection{NEGATIVE PROTRUSION}

Fowler and Nordheim described the field emission of electrons from metal electrodes [32,33]. The two main parameters for the calculation are the effective area $A_{\text {eff }}$ of emission and the field enhancement factor $\beta$. Consistent with previous works with similar electrode configurations, the effective area was chosen to $A_{\text {eff }}=10^{-12} \mathrm{~m}^{2}$ and is kept constant $[8,10,11]$.

The field enhancement factor depends on the geometry of the protrusion, in particular on the tip length $L$ and the tip radius $R$. The values $\beta_{L / R}$ for different geometries characterized by the ratio $L / R$ are described by the formula stated in [11]:

$$
\beta_{L / R}=a_{1} \cdot \exp \left(a_{2} \cdot \frac{L}{R}\right)+a_{3} \cdot \exp \left(a_{4} \cdot \frac{L}{R}\right)
$$

with $a_{1}=170, a_{2}=0.01, a_{3}=-235$ and $a_{4}=-0.4$. The field enhancement factor $\beta$ for HFO1234ze is pressure dependent similar to the observations in other gases, e.g. [10, 
11]. The enhancement factor for different pressures $p$ in Pascal for a certain protrusion geometry $L / R$ can be calculated by

$$
\beta=\beta_{L / R} \cdot 1.540 \cdot\left(\frac{p}{10^{5} \mathrm{~Pa}}\right)^{-0.862}
$$

The function is fitted to the experimental results of the entire pressure range investigated. For the $1 \mathrm{~mm}$ protrusion with $0.2 \mathrm{MPa}$ as depicted in Figure 2, the value of $\beta$ is 125 .

\subsubsection{POSITIVE PROTRUSION}

Free electrons for positive tips are provided by detachment from negative ions for electron attaching gases ([35] and references therein). As HFO1234ze is a strongly electron attaching gas, the same mechanism is assumed.

From the results in the swarm experiment [18] no detachment coefficient for HFO1234ze could be deduced. Thus, it was estimated by an inverse method: as input parameter for the estimation, the lower boundary of the statistical time lags for each pressure was fitted by a power function. The inverse of the statistical time lag $t_{\mathrm{s}}$ is the rate of detached electrons $\dot{N}_{\mathrm{e}}$. According to [9] $\dot{N}_{\mathrm{e}}$ can be calculated by:

$$
\dot{N}_{\mathrm{e}}=\Omega \cdot 4 \pi \cdot n^{-} \int_{l_{0}}^{l_{\mathrm{cr}}} \delta(E(z)) \cdot(z+R)^{2} \mathrm{~d} z
$$

The solid angle $\Omega \approx 0.1$ sr provides a lateral boundary for the critical volume in front of the tip [9]. The electric field strength $E(z)$ ahead of the protrusion is calculated according to the formula stated in [8]. The electrons need a minimal distance $l_{0}$ to the electrode surface to develop into an avalanche. The maximum distance $l_{\text {cr }}$ is given by the drop of the field strength $E(z)$ below the critical field strength.

The ions in the gas gap are mainly created by ionization from cosmic rays [38]. In the literature values are given for the ionization of air $\left(3 \mathrm{IP} \mathrm{cm}^{-3} \mathrm{~s}^{-1}\right.$ [42]) and $\mathrm{SF}_{6}\left(10 \mathrm{IP} \mathrm{cm}^{-3} \mathrm{~s}^{-1}\right.$ [43]) at atmospheric pressure due to cosmic rays. As these values are in the same order of magnitude, the equilibrium density of negative ions $n^{-}$in HFO1234ze is assumed to be similar and is chosen to be equal to the number density of $\mathrm{SF}_{6}$ [8]:

$$
n^{-}=p \cdot 2.2 \cdot 10^{4} \mathrm{~m}^{-3} \mathrm{~Pa}^{-1} \text {. }
$$

The detachment rate coefficient $\delta$ is depending on the field strength at a given point. Thus, no direct solution of the problem is possible. Therefore an inverse regression method is applied. This approach was tested with the detachment rate coefficient of $\mathrm{CF}_{4}$ and yielded good agreement to literature data. For HFO1234ze the detachment rate coefficient was determined to

$$
\delta\left(\frac{E}{E_{\text {crit }}}\right)=c \cdot 10^{\left(a \cdot\left(\frac{E}{E_{\text {crit }}}\right)^{b}\right)}
$$

with the coefficients $a=-6.947, b=-1.101$ and $c=$ $2.626 \cdot 10^{10} \mathrm{~s}^{-1}$. With this result the statistical time lags for the different pressures according to equation (4) are calculated in forward direction. As the ions are drifting towards the electrode and the remaining ion concentration is only maintained by the ionization due to cosmic radiation, it is assumed that $5 \mu \mathrm{s}$ after the voltage application the negative ion density lowers to $n^{-}=p \cdot 0.1 \mathrm{~m}^{-3} \mathrm{~Pa}^{-1}$. As before it is assumed that this value is similar to the one in $\mathrm{SF}_{6}$ and is taken from [8]. The computed theoretical curve for $0.2 \mathrm{MPa}$ is depicted in Figure 2 with the dashed-dotted line.

\subsection{CRITICAL FIELD STRENGTH}

With the swarm experiment it was only possible to determine the critical field strength of HFO1234ze up to $40 \mathrm{kPa}$ due to the strong pressure dependence. Additional measurements of the AC breakdown field strengths of the homogeneous field are performed for pressures up to $0.25 \mathrm{MPa}$. With the additional results the critical field strength $(E / N)_{\text {crit }}$ (in Townsend) in dependence on the pressure $p$ (in Pascal) can be described as

$$
(E / N)_{\mathrm{crit}}=305 \mathrm{Td} \cdot\left(1-\exp \left(-\frac{p+55 \mathrm{kPa}}{55 \mathrm{kPa}}\right)\right) \text {. }
$$

The critical field strength at $0.1 \mathrm{MPa}$ results in $287 \mathrm{Td}$. Above $0.15 \mathrm{MPa}$ deviations from the stationary value of $305 \mathrm{Td}$ are small.

On the basis of the breakdown experiments, the pressure independent value of the critical field strength of HFO1234ze is determined to $305 \mathrm{Td}$. This is $85 \%$ of the critical field strength of $\mathrm{SF}_{6}\left(E_{\mathrm{crit}, \mathrm{SF} 6}=360 \mathrm{Td}\right.$ [36]), which is within the standard deviation of the value calculated in [17] and slightly higher than the results of [13].

\subsection{SIMULATION PARAMETERS}

Figure 3 presents the results of the simulation according to section 2.1 together with the values determined from the experiments. The a priori unknown parameters are adapted to $C_{\mathrm{s} \text {,pos }}=1.5 \mathrm{~Pa} \mathrm{~m}, C_{\mathrm{s}, \text { neg }}=2.7 \mathrm{~Pa} \mathrm{~m}$ and $\alpha_{2}=0.03$. As the figure shows, the experimental values for the positive tip can be well modeled with these parameters. The measured results for the negative polarity at $0.1 \mathrm{MPa}$ and $0.15 \mathrm{MPa}$ are substantially lower than the calculated curves. For a pressure of $0.3 \mathrm{MPa}$ the experimental point for $x_{\max }$ could not be obtained due to the upper limit of the voltage source.

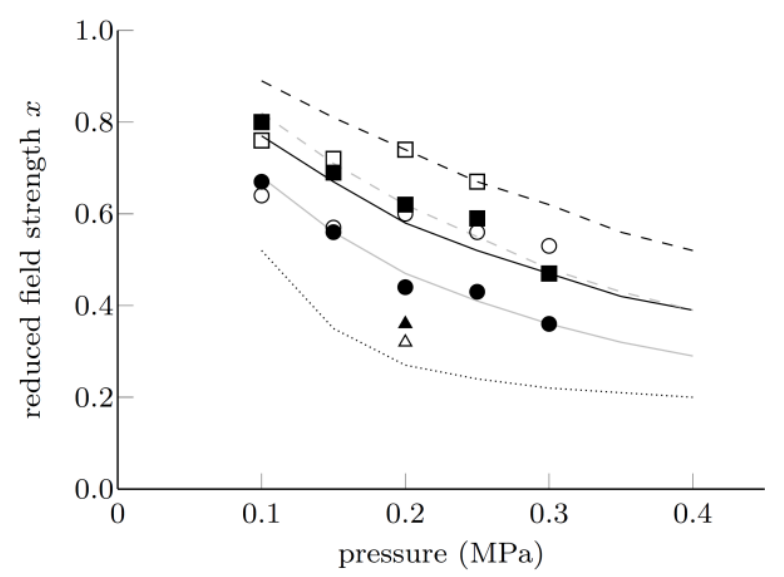

Figure 3. Calculated inception voltage (dotted line) and lower (solid line, gray: positive, black: negative) and upper (dashed line, gray: positive, black, negative) limit of delayed breakdowns together with the experimental results: $\Delta x_{\text {inc,pos }}, \Delta x_{\text {inc,neg }}, \bullet x_{\text {min,pos }}, \circ x_{\text {min,neg }}, \| x_{\text {max,pos }}, \square x_{\text {max,neg }}$. 
The reduced inception field strength $x_{\text {inc }}$ has very pronounced pressure dependence. The experimental data points for the streamer inception fields at $0.2 \mathrm{MPa}$ gained with the investigations with $\mathrm{x}$-rays are inserted into the graphic. They are slightly higher than the calculated inception field.

\subsection{DISCUSSION}

Qualitatively, the results of the measured time lags in HFO1234ze (figure 2) show the same behavior as known for $\mathrm{SF}_{6}$ [9], $\mathrm{C}_{3} \mathrm{~F}_{8}$ [10] and $\mathrm{CF}_{4}$ [11]. The pressure dependence of $x_{\min }$ and $x_{\max }$ can be traced by the simulation.

The results of the time lag measurements for the negative tip show a substantial range between the field of the first observed discharge and $x_{\min }$ for all pressures investigated. This is equal to the other gases. The results for the positive protrusion in HFO1234ze are very similar to the experiments in $\mathrm{C}_{3} \mathrm{~F}_{8}$ [10] and in $\mathrm{SF}_{6}$ [9]. In HFO1234ze for most pressures a small field range between the first occurrence of discharges without breakdown and the first delayed breakdown exist. This was slightly different in $\mathrm{C}_{3} \mathrm{~F}_{8}$ where the first observed discharge lead to breakdown. In $\mathrm{SF}_{6}$ this range was slightly larger than in HFO1234ze.

Regarding the $\mathrm{x}$-ray experiments with positive tip, the statistical time lags are limited to the delay of the $\mathrm{x}$-ray pulses of about $20 \mu \mathrm{s}$. The measurements in $\mathrm{SF}_{6}$ [31] and $\mathrm{CF}_{4}$ [11] show the same behavior. Hence, the $\mathrm{X}$-rays seem to provide sufficient electrons to start an avalanche. The discharge pattern observed in the negative case in HFO1234ze seems to be random. The inception field strength obtained in the second experiment run gives the same value as for the positive protrusion. But still the delayed discharges occurred even if free electrons are provided. As these delayed discharges are shifted towards lower field strengths compared to the measurements without x-rays, a certain influence of the artificially provided electrons cannot be excluded. This pattern was not seen in measurements with other gases.

The parameters $C_{\mathrm{s} \text {,pos }}, C_{\mathrm{s} \text {,neg }}$ and $\alpha_{2}$ determined from the time lag measurements in HFO1234ze are very similar to the ones obtained for $\mathrm{SF}_{6}$ [9] and $\mathrm{C}_{3} \mathrm{~F}_{8}$ [10]. With those values the experimental results of $x_{\min }$ and $x_{\max }$, particularly the positive ones, can be well modeled.

The simulated trends of $x_{\min }$ and $x_{\max }$ in HFO1234ze for the negative polarity do not fit as well to the experimental limits as for the positive tip (figure 3), especially for the pressures below $0.2 \mathrm{MPa}$. In $\mathrm{C}_{3} \mathrm{~F}_{8}$ only the measured values of $x_{\text {min }}$ deviate from the calculation, the $x_{\max }$ values in $\mathrm{C}_{3} \mathrm{~F}_{8}$ could be well reproduced. Therefore, a different discharge mechanism for $0.1 \mathrm{MPa}$ in $\mathrm{C}_{3} \mathrm{~F}_{8}$ was assumed to be responsible. In $\mathrm{CF}_{4}$ both, $x_{\text {min }}$ and $x_{\text {max }}$ revealed a weak pressure dependence compared to the simulation. In this gas most probably the reduced sensitivity to surface roughness causes this characteristic [11]. For HFO1234ze the figure of merit for the sensitivity to surface roughness according to [37] is with a value of approximately $7 \mathrm{~Pa} \mathrm{~m}$ for $0.2 \mathrm{MPa}$ similar to $\mathrm{SF}_{6}$ and $\mathrm{C}_{3} \mathrm{~F}_{8}$. The value for $0.1 \mathrm{MPa}$ is with approximately $13 \mathrm{~Pa} \mathrm{~m}$ nearly twice as high, but still well below the figure of merit of $\mathrm{CF}_{4}(26 \mathrm{~Pa} \mathrm{~m})$. The sensitivity to surface roughness is inversely proportional to the figure of merit. These values are consistent with the experiments in HFO1234ze, where good results were achieved with the $1 \mathrm{~mm}$ protrusion. Hence, the sensitivity of the gas was sufficient so that discharge development always started at the inhomogeneity. The behavior of the breakdown limits in HFO1234ze corresponds better to the results in $\mathrm{C}_{3} \mathrm{~F}_{8}$, as the experimental trend of $x_{\max }$ can be modeled quite well at $0.2 \mathrm{MPa}$ and higher. Only the flat behavior of $x_{\min }$ is not represented adequately.

The calculated reduced inception field strength $x_{\text {inc }}$ has very pronounced pressure dependence compared to $\mathrm{SF}_{6}, \mathrm{C}_{3} \mathrm{~F}_{8}$ and $\mathrm{CF}_{4}$ [9-11]. This can be explained by the still substantial pressure dependence of the critical field strength and the effective ionization coefficient in the pressure range up to $0.15 \mathrm{MPa}$. The experimentally determined inception points are roughly $10 \mathrm{kV}$ and $20 \mathrm{kV}$ higher than the result of the streamer criterion. The main reason is due to small tolerances in the experimental setup as discussed in [31].

\section{BREAKDOWN VOLTAGES IN DIFFERENT GEOMETRIES}

\subsection{RESULTS}

The results provided in section 3 form the basis for the prediction of the breakdown voltages in arbitrary field configurations. The breakdown voltages are calculated according to the model of Bujotzek and Seeger [8] as shortly described in section 2.3. Figure 4 shows the results for the geometries summarized in table 2, which represent typical field configurations of real high voltage equipment. The protrusion height of $300 \mu \mathrm{m}$ to $400 \mu \mathrm{m}$ gives an upper limit for arrangements with very rough surfaces. Small particles or surface damages are in the range of the $1 \mathrm{~mm}$ protrusion. Very long particles can reach $20 \mathrm{~mm}$. These conditions result in very different field distributions covering many interesting cases.

For all three geometries the simulated reduced breakdown fields for positive and negative lightning impulse are higher than for $\mathrm{AC}$ voltages. The positive lightning impulse breakdowns have lower breakdown field strengths than the negative impulses, except for the configuration with the smallest protrusion height where both breakdown fields are quite similar over the calculated pressure range. An increasing protrusion length reduces the breakdown withstand of the gap.

To verify the simulation results, classical breakdown experiments are performed as described in section 2.4. The mean breakdown voltage and twice the standard deviation are depicted in figure 4 for the configurations with a high surface roughness and with a $20 \mathrm{~mm}$ protrusion. For AC the peak values are plotted. Additionally, for the $1 \mathrm{~mm}$ protrusion the reduced field strength of the first breakdown occurring less than $1 \mathrm{~s}$ (relevant for $\mathrm{AC}$ breakdown) or less than $1 \mu \mathrm{s}$ (relevant for lightning impulse breakdown), respectively, after voltage rise are taken from the time lag measurements and included in the picture with the simulated breakdown voltages.

The experimental results for the AC breakdown in the homogeneous field configuration with the $400 \mu \mathrm{m}$ protrusion are slightly below the calculated ones, but the simulated curve is within twice the standard deviation. For the breakdown measurements with lightning impulses the roughness of the electrodes was less than for AC. For both pressures and both 
polarities the experimental mean LI breakdown voltages are equal. The measurements of the positive LI correspond to the simulated data. The deviation for the negative case is higher.
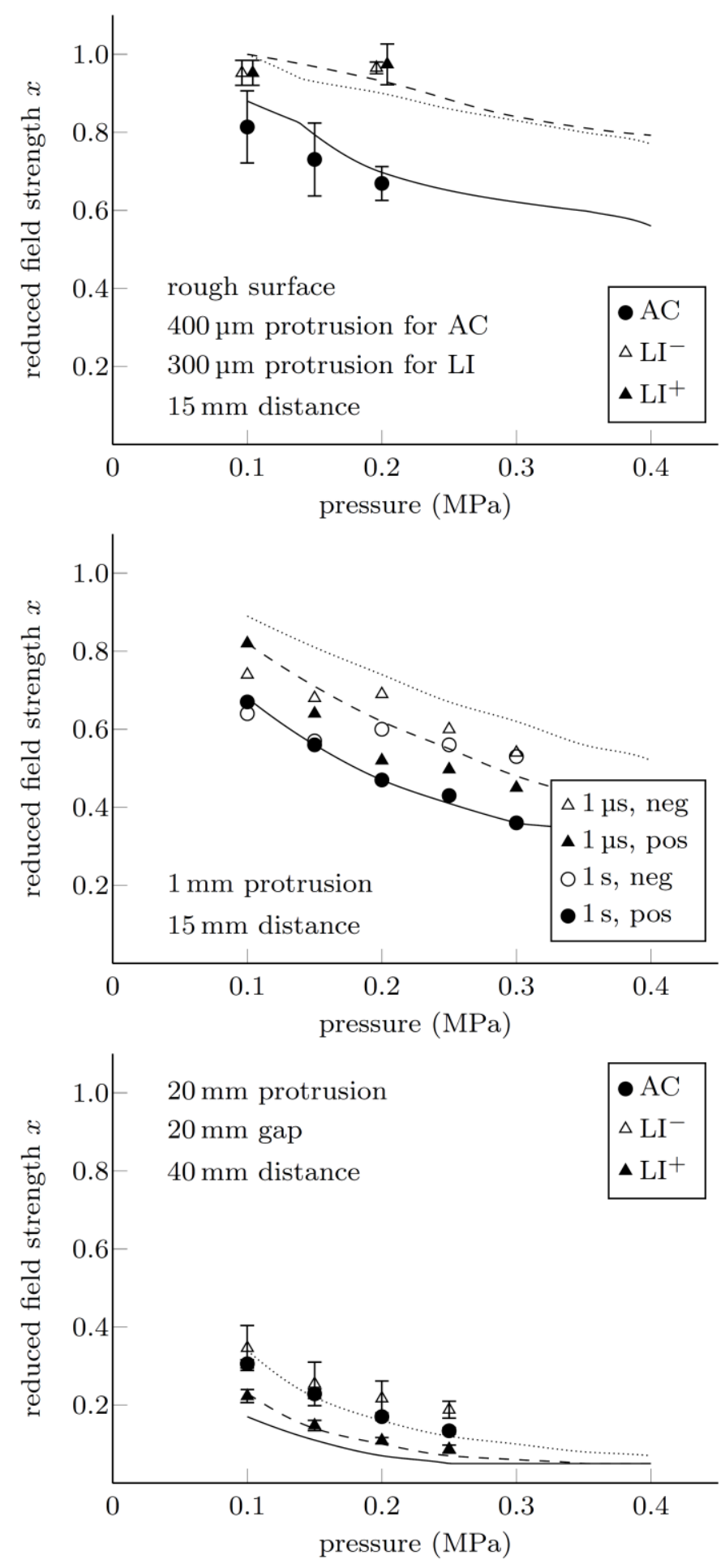

Figure 4. Results of the simulation (AC (solid), $\mathrm{LI}^{+}$(dashed), $\mathrm{LI}^{-}$(dotted)) and the measurements of breakdown voltages in different field geometries. The experimental results are plotted with twice the standard deviation. For $1 \mathrm{~mm}$ the "experimental results" are derived from the time lag measurements.

Regarding the experimental results for the very inhomogeneous field with the $20 \mathrm{~mm}$ protrusion, the lightning impulse breakdown voltages agree very well with the prediction, except for the negative points at $0.2 \mathrm{MPa}$ and $0.25 \mathrm{MPa}$ which are slightly too high. The pressure dependence of the results of the AC breakdown measurement is as expected, but the breakdown field strengths are too high. The values are in between the results for positive and negative lightning impulse breakdown.

Table 2. Geometries used for the calculation of the breakdown field strengths. The electrode distance includes the protrusion height.

\begin{tabular}{ccc}
$\begin{array}{c}\text { Protrusion } \\
\text { height }\end{array}$ & $\begin{array}{c}\text { Protrusion } \\
\text { radius }\end{array}$ & $\begin{array}{c}\text { Electrode } \\
\text { distance }\end{array}$ \\
\hline $400 \mu \mathrm{m}$ & $200 \mu \mathrm{m}$ & $15 \mathrm{~mm}$ \\
$300 \mu \mathrm{m}$ & $200 \mu \mathrm{m}$ & $15 \mathrm{~mm}$ \\
$1 \mathrm{~mm}$ & $200 \mu \mathrm{m}$ & $15 \mathrm{~mm}$ \\
$20 \mathrm{~mm}$ & $200 \mu \mathrm{m}$ & $40 \mathrm{~mm}$ \\
\hline
\end{tabular}

For the $1 \mathrm{~mm}$ protrusion no additional breakdown measurements are performed. For a first estimation, values from the time lag measurements are depicted as described above. For the AC breakdown, values for both polarities are included. The simulation predicts that the positive polarity is determining the breakdown. This corresponds to the experimental data as the positive values agree well with the simulated curve. The negative values are similar or higher than the positive ones. Regarding the lightning impulse breakdown voltages, the simulated data represents an upper boundary of the experimental data.

\subsection{DISCUSSION}

The overall comparison between the prediction of the breakdown voltages of the quite different field configurations and the experimentally obtained mean breakdown voltages reveals a good agreement. The level of the simulated curves is mostly within twice the standard deviation of the measured values.

During the AC experiments with the rough electrodes, breakdowns occurred in the positive and in the negative half cycle of the voltage. The fraction of breakdowns in the positive half of the $\mathrm{AC}$ voltage (i.e. positive polarity at the rough surface) increases from $7.3 \%$ to $19.5 \%$ and $48.8 \%$ with increasing pressure. This coincides with the simulation which predicts that the negative half would be decisive up to $0.14 \mathrm{MPa}$, then changing to the positive half. For the LI case the simulations show that a small change in the protrusion height results in substantial changes of the breakdown field strengths. Thus, for a matching of the predicted and measured breakdown fields an exact knowledge of the protrusion geometry or the surface roughness, respectively, is essential.

The simulation of the $1 \mathrm{~mm}$ protrusion predicts that the positive half of the AC voltage is decisive for the breakdown. Although the inserted experimental data represent the lowest breakdown voltage, they agree very well with the simulation. For the lightning impulse breakdown voltages the calculations represent an upper boundary. The determination of a mean breakdown voltage from the time lag measurements is not possible. Nevertheless, the mean voltage would be higher than the shown values. An indicative measurement of the mean lightning breakdown voltages at $0.3 \mathrm{MPa}$ give evidence to this assumption. 
The discrepancy between the calculated and the measured AC breakdown voltages for the $20 \mathrm{~mm}$ protrusion is substantial. The results are higher than the positive but lower than the negative lightning impulse breakdowns. A revision of the electrodes and a second determination of the $\mathrm{AC}$ breakdown voltages were done to exclude experimental problems and to confirm the results. It is not possible to predict such behavior with the model, but most probably this could be explained by corona stabilization. On the one hand, the breakdown field strength for lightning impulse voltage application was predicted very well for both polarities. On the other hand, the model does not take into account the influence of space charges. As the AC voltage is increased during the experiment, first the discharge inception limit is reached and space charge can be created. This space charge may lead to an increased breakdown voltage [2, S. 199][38].

Due to the breakdowns, black deposit was found on the electrodes after the experiments. For HFOs it is known that carbon dust precipitation occurs due to the spark-overs [13]. This is a drawback for the use in high voltage insulation as carbon is a good conductor and therefore, insulating surfaces could be short-circuited. But in literature several approaches are described to prevent carbonization $[39,40]$.

HFO1234ze cannot be used as pure insulation gas for high voltage equipment due to the high boiling point. But it could serve as insulation in the medium voltage range, for example in ring main units on the secondary distribution level. Simulations with representative geometries suggest that it will not be necessary to increase the pressure (normally about $0.14 \mathrm{MPa}$ ) when replacing the $\mathrm{SF}_{6}$ by $\mathrm{HFO} 1234$ ze to maintain the same insulation performance. Only the operation temperature would have to be limited to $-10^{\circ} \mathrm{C}$ to $-15^{\circ} \mathrm{C}$ to avoid liquefaction [41].

\section{CONCLUSION AND OUTLOOK}

In recent work an existing model for the prediction of breakdown field strengths in arbitrary field configurations under AC and lightning impulse voltage stress was adapted to electron attaching gases other than $\mathrm{SF}_{6}$. In this contribution, the prediction method was successfully applied to a mostly unknown molecule for the first time. All parameters necessary for the calculations are derived from swarm parameters, the thermodynamic quantities are calculated and the remaining ones can be extracted from the time lag measurements. The results obtained by classic breakdown experiments agree well with the calculations, except for the AC breakdown in the very inhomogeneous configuration, as discussed. Thus, it seems that the model can be applied to predict the breakdown behavior of unknown gases in a wide range of applications. Still, it is necessary to bear in mind the limitations of the model. To further extend the scope of the method, investigations of weakly inhomogeneous background fields will be subject of further research. Additionally, the prediction of the breakdown voltages in larger "real world" field configurations will need a more detailed calculation of the ion densities depending on the applied voltage waveform.

The value of the critical field strength of HFO1234ze is in an interesting range. But unfortunately, the boiling point is quite high and the gas liquefies already at around $0.42 \mathrm{MPa}$ at room temperature. Therefore, it will not suit as pure insulation gas but could be used as an admixture in high voltage gaseous insulations. For the use of HFO1234ze as part of a mixture, a synergistic effect with other gas, especially with commonly used buffer gases such as $\mathrm{N}_{2}, \mathrm{CO}_{2}$ or synthetic air, would be of great interest and has to be investigated. On the other hand, HFO1234ze can most probably be used as replacement for $\mathrm{SF}_{6}$ in medium voltage applications. The disadvantage of carbon dust precipitation has to be prevented by appropriate measures.

\section{REFERENCES}

[1] J. C. Devins, "Replacement gases for SF6", IEEE Trans. Electr. Insul., Vol. 15, pp. 81-86, 1980.

[2] G. Biasiutti, Neue Isoliergas für gekapselte Hochspannungsanalgen, Ph.D. Thesis, ETH Zurich, Switzerland, 1985 (in German).

[3] L. G. Christophorou, J. K. Olthoff and D. S. Green, "Gases for electrical insulation and arc interruption: possible present and future alternatives to pure SF$_{6}$ ", NIST Technical Note 1425, National Institute of Standards and Technology, Washington, DC, USA, 1997.

[4] L. Niemeyer, "A systematic search for insulation gases and their environmental evaluation", Gaseous Dielectrics VIII, L. G. Christophorou (Ed.), Kluwer, New York, pp. 459-464, 1998.

[5] H. Okubo and N. Hayakawa, "Dielectric characteristics and electrical insulation design techniques of gases and gas mixtures as alternatives to SF6", Gaseous Dielectrics X, L. G. Christophorou (Ed.), Springer, New York, pp. 243-252, 2004

[6] C. M. Franck, D. A. Dahl, M. Rabie, P. Haefliger and M. Koch, "An efficient procedure to identify and quantify new molecules for insulating gas mixtures", Contr. Plasma Phys., Vol. 54, pp. 3-13, 2014.

[7] M. Seeger, L. Niemeyer and M. Bujotzek, "Leader propagation in uniform background fields in $\mathrm{SF}_{6}$ ", J. Phys. D: Appl. Phys., Vol. 42, $185205,2009$.

[8] M. Bujotzek and M. Seeger, "Parameter dependence of gaseous insulation in $\mathrm{SF}_{6}$ ", IEEE Trans. Dielectr. Electr. Insul., Vol. 20, pp. 854$855,2013$.

[9] M. Seeger, L. Niemeyer and M. Bujotzek, "Partial discharges and breakdown at protrusions in uniform background fields in SF6", J. Phys. D: Appl. Phys., Vol. 41, 185204, 2008.

[10] M. Koch and C. M. Franck, "Partial discharges and breakdown in C3F8", J. Phys. D: Appl. Phys., Vol. 47, 405203, 2014.

[11] M. Koch and C. M. Franck, "Prediction of partial discharge and breakdown voltages in $\mathrm{CF}_{4}$ for arbitrary electrode geometries", J. Phys. D: Appl. Phys., Vol. 48, 055207, 2015.

[12] US Patent 8080 185, M. H. Luly, R. G. Richard, "Gaseous dielectrics with low global warming potentials", 2011.

[13] Y. Kieffel, A. Girodet, F. Biquez, Ph. Ponchon, J, Owens, M. Costello, M. Bulinski, R. Van San and K. Werner, "SF 6 alternative development for high voltage switchgears", Cigré, D1-305, 2014.

[14] International patent WO 2013/004798 Al, Y. Kieffel, A. Girodet, D. Piccoz and R. Maladen, "Use of a mixture comprising a hydrofluoroolefin as a high-voltage arc-extinguishing and/or insulating gas and high-voltage electrical device comprising same", January 10, 2013.

[15] M. Rabie and C. M. Franck, "Computational screening of new high voltage insulation gases with low global warming potential", IEEE Trans. Dielectr. Electr. Insul., Vol.22, pp. 196-302, 2015.

[16] Honeywell, safety data sheet HFO1234ze(E), version 1.7, revision date 24 January 2014.

[17] M. Rabie, predicted critical field strength of HFO1234ze, private communication, 2014

[18] A. Chachereau, swarm parameters of HFO1234ze, private communication, 2014

[19] Word Meteorological Organization, "Scientific Assessment of Ozone Depletion: 2014" Global Ozone Research and Monitoring Project, Report No. 56, 2014.

[20] A. B. Pearson, "R-1234ze for variable speed centrifugal chillers", Proc. Institute of Refrigeration, session 2012-13, 2013.

[21] P. J. Linstrom and W. G. Mallard (Eds.), "NIST Chemistry WebBook, NIST Standard Reference Database Number 69", National Institute of Standards and Technology, Gaithersburg MD, http://webbook.nist.gov, 
retrieved October 10, 2014; HFO1234ze: http://wtt-pro.nist.gov/wttpro/index.html?cmp=r-1234ze\#1.3.3.3-tetrafluoro-1-propene

[22] Y. Higashi, "Thermophysical properties of HFO-1234yf and HFO1234ze(E)", Int'l. Sympos. Next-generation Air Conditioning and Refrigeration Technology, Japan, 2010.

[23] Honeywell, safety data sheet HFO1234yf, version 1.11, revision date 15 July 2008.

[24] M. S. Javadi, R. Søndergaard, O. J. Nielsen, M. D. Hurley and T. J. Wallington, "Atmospheric chemistry of trans- $\mathrm{CF}_{3} \mathrm{CH}=\mathrm{CHF}$ : products and mechanisms of hydroxyl radical and chlorine atom initiated oxidation", Atmos. Chem. Phys., Vol. 8, pp. 3141-3147, 2008.

[25] S. Henne, D. E. Shallcross, S. Reimann, P. Xiao, D. Brunner, S. O'Doherty and B. Buchmann, "Future emissions and atmospheric fate of HFC-1234yf from mobile air conditioners in Europe", Environ. Sci. Technol., Vol. 46, pp 1650-1658, 2012.

[26] L. Niemeyer, L. Ullrich and N. Wiegart, "The mechanism of leader breakdown in electronegative gases", IEEE Trans. Electr. Insul., Vol. 24, pp. 309-324, 1989.

[27] D. Goodwin, N. Malaya, H. Moffat and R. Speth, "Cantera: An object oriented software toolkit for chemical kinetics, thermodynamics, and transport processes", https://code.google.com/p/cantera/, 2013.

[28] E. Goos, A. Burcat and B. Ruscic, "Extended Third Millennium Ideal Gas and Condensed Phase Thermochemical Database for Combustion with Updates from Active Thermochemical Tables", http://burcat.technion.ac.il/dir/, retrieved 19 August 2014.

[29] K. Petcharaks, Applicability of the streamer breakdown criterion to inhomogeneous gas gaps, Ph.D. thesis, ETH Zurich, Switzerland, 1995

[30] S. Adili and C. M. Franck, "Application of pulsed x-ray induced partial discharge measurements", IEEE Trans. Dielectr. Electr. Insul., Vol. 19, pp. 1833-1839, 2012.

[31] M. Koch, M. Bujotzek and C. M . Franck, "Inception level of discharges in $\mathrm{SF}_{6}$ induced with short $\mathrm{x}$-ray pulses", Conf. on Electrical Insulation and Dielectric Phenomena, pp. 11-14, 2014.

[32] R. H. Fowler and L. Nordheim "Electron emission in intense electric fields", Proc. Roy. Soc. Lond. A, Vol. 119, pp. 173-181, 1928.

[33] R. Latham, High Voltage Vacuum Insulation: Basic Concepts and Technological Practice, Academic Press, London, Ch. 2 and 4, 1995

[34] W. Hauschild and W. Mosch, Statistik für Elektrotechniker, VEB Verlag Technik, Berlin, $1^{\text {st }}$ edition, 1984, (in German).

[35] L. G. Christophorou and L. A. Pinnaduwage, "Basic physics of gaseous dielectrics", IEEE Trans. Electr. Insul., Vol. 25, pp. 55-74, 1990.

[36] L. G. Christophorou and J. K. Olthoff, Fundamental Electron Interactions with Plasma Processing Gases, Springer, Boston, 2004.
[37] G. Biasiutti, "Homogeneous field breakdown strength characteristic of some dielectric gases", Gaseous Dielectrics III (ed. L. Christiophorou), Pergamon Press, New York, pp. 174-182, 1982.

[38] E. Kuffel, W. S. Zaengl and J. Kuffel, High Voltage Engineering: Fundamentals, Elsevier, Amsterdam, $2^{\text {nd }}$ edition, 2000.

[39] L. G. Christophorou, D. R. James, I. Sauers, M. O. Pace, R. Y. Pai and A. Fatheddin, "Ternary gas dielectrics", Gaseous Dielectrics III (ed. L. Christiophorou), Pergamon Press, New York, pp. 151-163, 1982.

[40] US Patent 3184 533, B. J. Eiseman, Jr. "Method and apparatus for preventing carbon deposits in electrical apparatus containing electronegatively substituted dielectric fluids", May 18, 1965.

[41] Honeywell, HFO1234ze, "New Low Global Warming Potential Aerosol Propellant", Brochure, 2011.

[42] A. Hensen and J. C. H. van der Hage, "Parametrization of cosmic radiation at sea level", J. Geophys. Res., Vol. 99, pp. 10693-10695, 1994

[43] N. Wiegart et al., "Inhomogeneous field breakdown in GIS - The prediction of breakdown probabilities and voltages, Part II: Ion density and statistical time lag", IEEE Trans. Pow. Del., Vol. 3, pp. 931-938, 1988

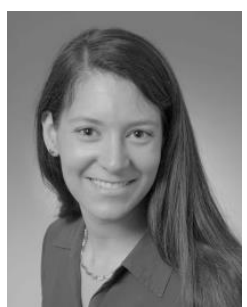

Myriam Koch (S'13) received a diploma degree in electrical engineering and information technology from RWTH Aachen University, Germany in 2010. In 2011 she joined the Power Systems and High Voltage Laboratories at ETH Zurich, Switzerland, where she is working towards her Ph.D. degree. Her current research addresses the modeling of partial discharge and breakdown behavior in potential replacement gases for $\mathrm{SF}_{6}$.

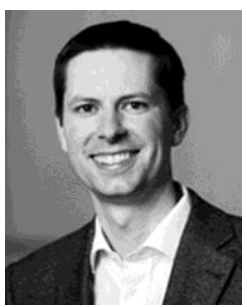

Christian M. Franck (M'04-SM'11) received a diploma in physics from the University of Kiel, Germany in 1999 and the Ph.D. degree in physics from the University of Greifswald, Germany in 2003. $\mathrm{He}$ was with the Swiss corporate research center of ABB during 2003-2009 as a Scientist and Group Leader for gas circuit breakers and high voltage systems. Currently, he is an Assistant Professor for High Voltage Technology at the Swiss Federal Institute of Technology (ETH), Zurich, Switzerland. 